\title{
p53 Promoted Ferroptosis in Ovarian Cancer Cells Treated with Human Serum Incubated- Superparamagnetic Iron Oxides
}

This article was published in the following Dove Press journal:

International Journal of Nanomedicine

\begin{abstract}
Yunhan Zhang, ',* Meihui Xia, ${ }^{2, *}$ Zizhen Zhou, ${ }^{3}$ Xiaoqing $\mathrm{Hu}$, (iD) ${ }^{\prime}$ Jiabin Wang, (ID) Meiyu Zhang, ${ }^{3}$ Yi Li, ${ }^{4}$ Liankun Sun,' Fangfang Chen, (iD) ${ }^{4,5}$ Huimei Yu ${ }^{1,6}$

'Key Laboratory of Pathobiology, Ministry of Education, Department of Pathophysiology, College of Basic Medical Sciences, Jilin University, Changchun I3002I, People's Republic of China; ${ }^{2}$ Department of Obstetrics \& Gynecology, The First Hospital of jilin University, Changchun, Jilin I3002 I, People's Republic of China; ${ }^{3}$ Clinical Medical College, Jilin University, Changchun I3002I, People's Republic of China; ${ }^{4}$ State Key Laboratory of Inorganic Synthesis and Preparative Chemistry, College of Chemistry, Jilin University, Changchun, Jilin I300 I2, People's Republic of China; ${ }^{5}$ Department of Gastrointestinal, Colorectal and Anal Surgery, China-Japan Union Hospital of jilin University, Changchun, Jilin 1 30033, People's Republic of China; ${ }^{6}$ Animal Experiment Center, College of Basic Medical Sciences, Jilin University, Changchun I3002I, People's Republic of China
\end{abstract}

*These authors contributed equally to this work

Correspondence: Huimei Yu Key Laboratory of Pathobiology, Ministry of Education, Department of

Pathophysiology, College of Basic Medical Sciences, Jilin University, Changchun

| 3002 I, People's Republic of China

Tel +86 43I 85619485

Email yuhuimei@jlu.edu.cn

Fangfang Chen

Department of Gastrointestinal, Colorectal and Anal Surgery, China-Japan Union Hospital of Jilin University,

Changchun, Jilin 130033, People's

Republic of China

Tel +86 43I 849953I2

Email cff@jlu.edu.cn
Methods: In this study, we used MTT assays to demonstrate that a combination of SPIOSerum and wild-type p53 overexpression can reduce ovarian cancer cell viability in vitro. Prussian blue staining and iron assays were used to determine changes in intracellular iron concentration following SPIO-Serum treatment. TEM was used to evaluate any mitochondrial damage induced by SPIO-Serum treatment, and Western blot was used to evaluate the expression of the iron transporter and lipid peroxidation regulator proteins. JC-1 was used to measure mitochondrial membrane potential, and ROS levels were estimated by flow cytometry. Finally, xCT protein expression and mitochondrial ROS levels were confirmed using fluorescence microscopy.

Results: SPIO-Serum effectively induced lipid peroxidation and generated abundant toxic ROS. It also facilitated the downregulation of GPX4 and XCT, ultimately resulting in iron-dependent oxidative death. These effects could be reversed by iron chelator DFO and lipid peroxidation inhibitor Fer-1. SPIO-Serum treatment disrupted intracellular iron homeostasis by regulating iron uptake and the cells presented with missing mitochondrial cristae and ruptured outer mitochondrial membranes. Moreover, we were able to show that p53 contributed to SPIO-Serum-induced ferroptosis in ovarian cancer cells.

Conclusion: SPIO-Serum induced ferroptosis and overexpressed p53 contributed to ferroptosis in ovarian cancer cells. Our data provide a theoretical basis for ferroptosis as a novel cell death phenotype induced by nanomaterials.

Keywords: ferroptosis, SPIO, p53, TF, xCT, iron-based nanomaterials

\section{Introduction}

Ferroptosis, an iron-dependent programmed cell death characterized by lipid peroxide accumulation, is genetically, biochemically, and morphologically distinct from other forms of regulated cell death. ${ }^{1,2}$ Unlike apoptosis, ferroptosis caused by lipid ROS accumulation with characteristics mainly of cytological changes, including decreased or vanished mitochondria cristae, a ruptured outer mitochondrial membrane, and a condensed mitochondrial membrane. ${ }^{1}$ Although iron affects the biological behavior of various tumor cells, how intracellular iron regulates the fate of these cells is poorly understood. ${ }^{3}$ An equally important question concerns how to increase iron levels in target cells both for in vitro cell culture studies and in vivo modeling. We address both these questions with respect to two ovarian cancer cell lines in this report. 
Iron promotes matrix metalloproteinase (MMP) and interleukin-6 (IL-6) synthesis in ovarian cancer cells, improves invasion, and metastasis. ${ }^{4,5}$ In addition, irondependent cell death results from an increase in intracellular lipid oxygen free radicals and an imbalance in redox homeostasis. ${ }^{6-8}$ Other factors can influence the effect of ferroptosis. One gene associated with augmenting ferroptosis is p53 which acts by mediating cell cycle arrest, senescence, and apoptosis. ${ }^{9-11}$ Additionally, p53 inhibits SLC7A11 (xCT) expression, a key component of the cystine/glutamate reverse transporter, ${ }^{12,13}$ making cells more sensitive to iron by increasing $\mathrm{H}_{2} \mathrm{O}_{2}$ and lipid peroxide levels. $^{14-16}$

Iron-based nanomaterials can be used as anticancer agents, ${ }^{17,18}$ such as iron oxide nanoparticles, iron-doped nanomaterials, iron-based metal-organic frameworks, and so on, as they induce excessive ROS production and trigger ferroptosis in cells. ${ }^{19,20}$ Their ability of generating ROS is regarded as the key role in achieving gratifying therapeutic effect. ${ }^{21-23} \mathrm{~A}$ recent discovered iron-based nanomaterials, metal-organic network-MON, was designed to induce oxidative stress and eradicate tumor cells through ferroptosis pathway. ${ }^{22}$ Another study found that localized heterogeneous Fenton reaction could be initiated by single-atom $\mathrm{Fe}$ nanocatalysts for competent nanocatalytic cancer therapy. ${ }^{24}$

In this study, SPIO-nanoworms pre-incubated with human serum (SPIO-Serum) induced ferroptosis in human ovarian cancer cells, showing the potential of iron nanomaterials to be used in tumor therapy.

\section{Materials and Methods}

\section{Key Materials} SPIO Nanoworms

SPIO nanoworms were synthesized in Dr. Simberg's laboratory as previously reported. ${ }^{25}$ Transmission electron microscopy (TEM) results showed the average length and width of the multi-iron oxide crystals were $103.2 \pm 38.0$ $\mathrm{nm}$ (s.d.) and $7.0 \pm 1.4 \mathrm{~nm}$ (s.d.), respectively (Figure 1A left). The hydrodynamic diameter which included both the iron oxide core and dextran shell was $140 \pm 6.5 \mathrm{~nm}$.

\section{SPIO-Serum}

SPIO-nanoworms were incubated with human serum at $37^{\circ} \mathrm{C}$ for $30 \mathrm{~min}$ and washed 3 times using PBS by ultracentrifuge at $55,000 \mathrm{~g}$ for $5 \mathrm{~min}$ at $4^{\circ} \mathrm{C}$. TEM showed a serum protein corona closely associated with the iron oxide core (Figure 1A right).

\section{SPIO-FBS}

SPIO-nanoworms were incubated with $\mathrm{FBS}$ at $37^{\circ} \mathrm{C}$ for 30 min and washed 3 times using PBS by ultracentrifuge at $55,000 \mathrm{~g}$ for $5 \mathrm{~min}$ at $4^{\circ} \mathrm{C}$.

\section{Reagents}

3-(4,5-dimethylthiazol-2-yl)-2,5-di-phenyltetrazolium bromide (MTT) was purchased from Sigma-Aldrich (St. Louis, MO, USA). Deferoxamine was purchased from Abcam (Cambridge, MA, USA). Ferrostatin-1 and erastin were purchased from MedChemExpress (Princeton, NJ, USA). The following antibodies were used: anti- $\beta$ actin, anti-p53 (Proteintech, Chicago, IL, USA); antiGPX4, anti-xCT, anti-TF, anti-TFR (Abcam, Cambridge, MA, USA).

\section{Methods}

\section{Cell Lines and Cell Culture}

SKOV3 cells were purchased from the Chinese Academy of Medical Sciences and Peking Union Medical College (Beijing, China). A2780 cells were purchased from American Tissue Culture Collection (Rockville, MD, USA). These cells were cultured in RPMI-1640 (Gibco Life Technologies, Carlsbad, CA, USA) supplemented with $10 \%$ fetal bovine serum (FBS) (Invitrogen, Carlsbad, CA, USA) at $37^{\circ} \mathrm{C}, 5 \% \mathrm{CO}_{2}$ concentration.

\section{Human Serum}

Whole blood was taken at China-Japan Union Hospital of Jilin University from five healthy volunteers after physical examination and obtaining informed consent. The study was approved by the Institutional Ethics Committee of ChinaJapan Union Hospital, Jilin University, Changchun, China. Human serum was pooled and stored at $-80^{\circ} \mathrm{C}$.

\section{Cell Viability Assay}

Cells were plated at $8 \times 10^{3}$ cells per well on 96 -well plates. After $24 \mathrm{~h}$, cells were treated with different concentrations of SPIO, SPIO-FBS, and SPIO-Serum. Also, cells were treated with SPIO-Serum or erastin for $24 \mathrm{~h}$ with other cotreatment. Cell viability was detected using an MTT assay, the result was measured by Vmax Microplate Reader (Molecular Devices, LLC, Sunnyvale, CA, USA) at $570 \mathrm{~nm}$.

\section{Intracellular Iron Staining}

After treatment, cells were washed 3 times with PBS to remove free iron, and fixed with $4 \%$ paraformaldehyde for $10 \mathrm{~min}$. Prussian blue staining was used to visualize 
A
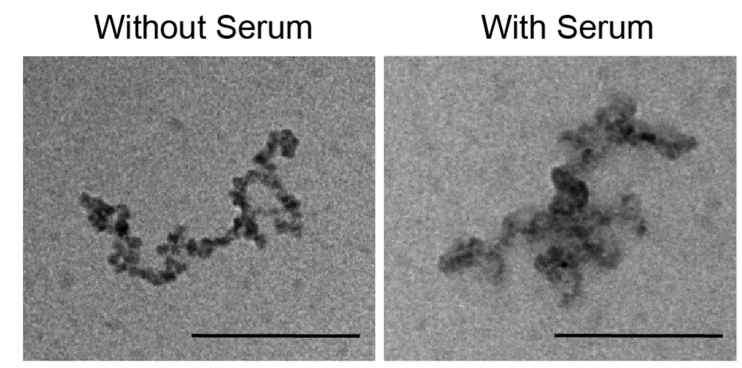

C
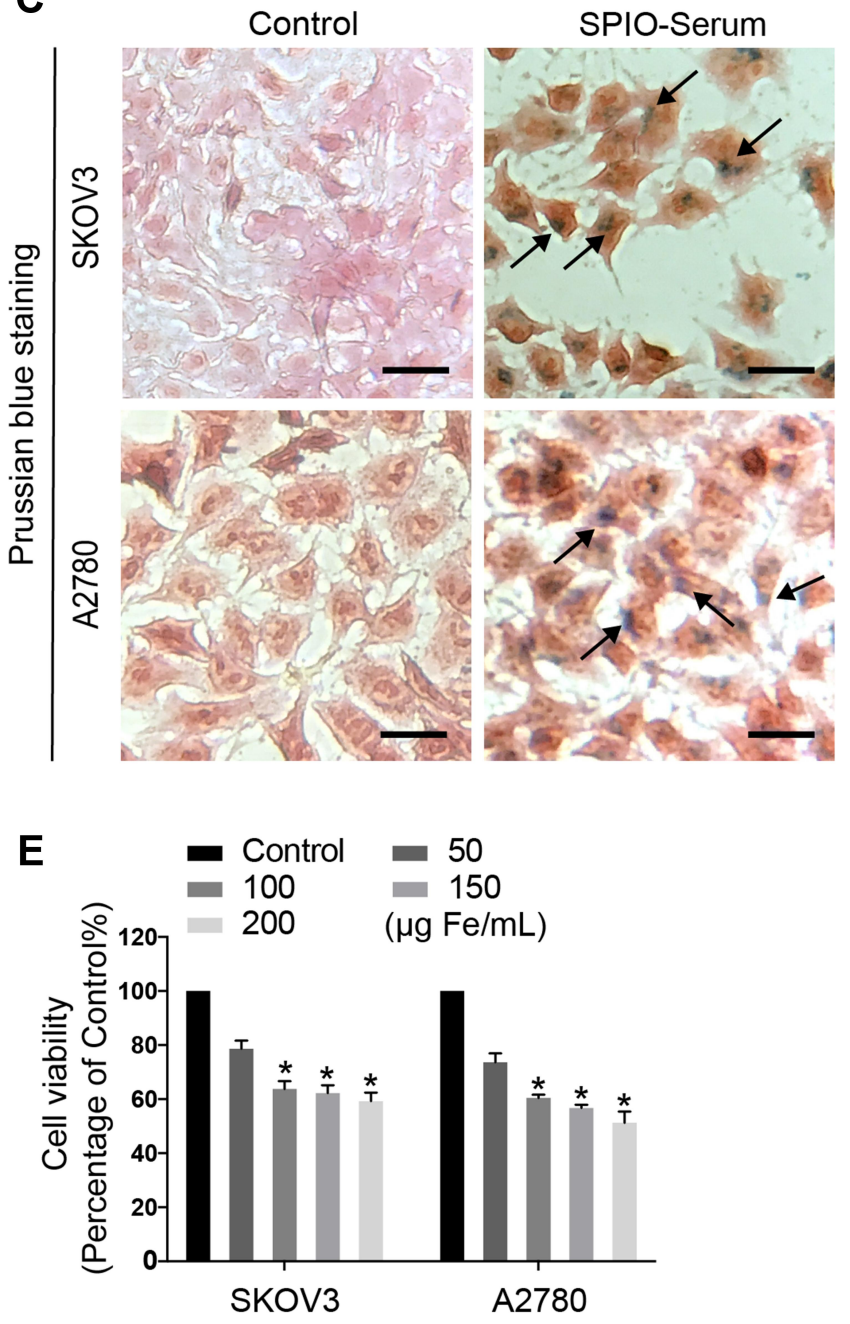

B $\quad$ SPIO

SPIO-Serum
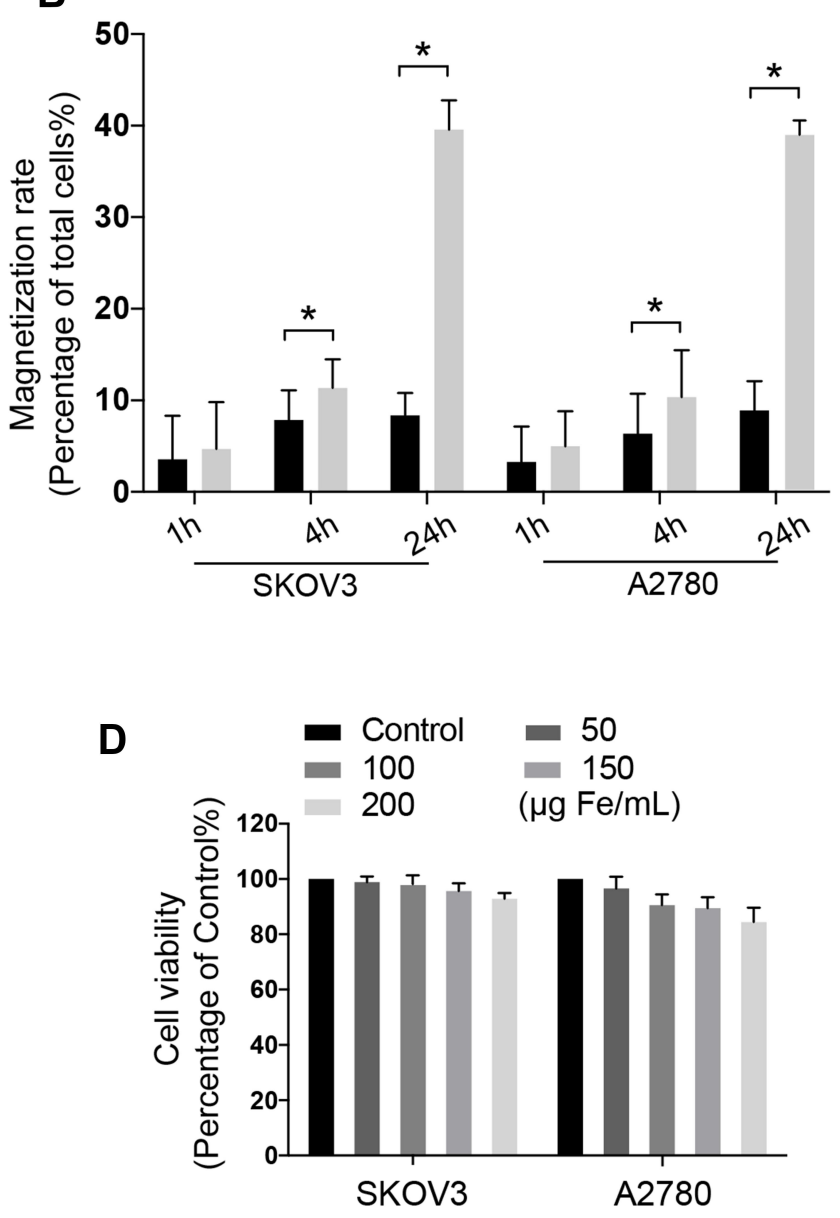

$\mathbf{F}$

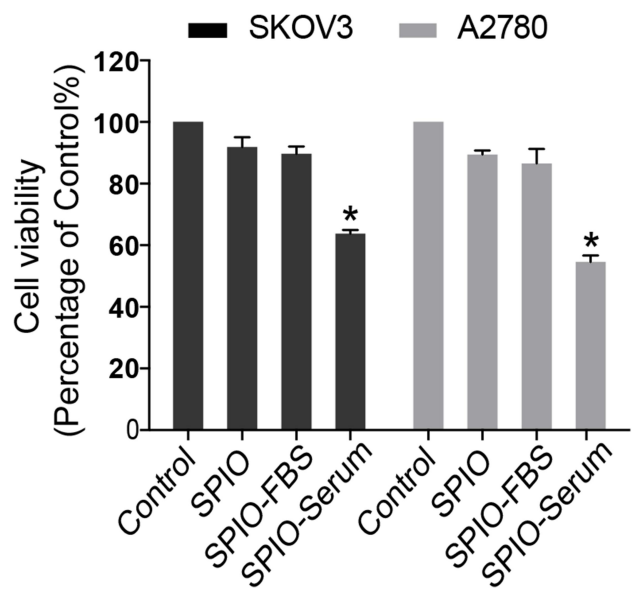

Figure I SPIO-Serum inhibited ovarian cancer cells proliferation. (A) TEM images. SPIO nanoworms before and after incubated with serum were characterized by TEM. (Scale bar: $100 \mathrm{~nm}$ ). (B) Assessment of SPIO nanoworms uptaken with or without incubation in human serum for I h, 4 h, and 24 h. (C) Prussian blue staining showed ironcontaining cells (Scale bar: $20 \mu \mathrm{m}$ ). (D) Ovarian cancer cells SKOV3 and A2780 were treated with SPIO (0, 50, 100, 150, and 200 $\mu \mathrm{g}$ Fe/mL) for $24 \mathrm{~h}$, MTT assay result showed SPIO had almost no cytotoxicity effect on cells. (E) Ovarian cancer SKOV3 and A2780 cells were treated with SPIO-Serum (0, 50, I00, I50, and 200 $\mu$ g Fe/mL) for 24 h. MTT assay result showed that SPIO-Serum inhibited SKOV3 and A2780 cells viability in a dose-dependent manner. (F) SKOV3 and A2780 cells were treated with SPIO, SPIO-FBS or SPIO-Serum ( $100 \mu \mathrm{g} \mathrm{Fe} / \mathrm{mL})$ for $24 \mathrm{~h}$. $100 \mu \mathrm{g} \mathrm{Fe} / \mathrm{mL}$ SPIO-Serum was used in the subsequent experiments. All data presented the mean $\pm \mathrm{SD}(\mathrm{n}=6)$. $* P<0.05$ vs control group.

Abbreviations: SKOV3, A2780, ovarian cancer cells; SPIO, superparamagnetic iron oxide; FBS, fetal bovine serum. 
intracellular iron following the manufacturer's protocol (Catalog number DJ0008, Leagene, China).

\section{Total Cellular Iron}

Total iron levels were measured according to the protocol of iron assay from Dr. Simberg's laboratory. Cells were homogenized on ice and centrifuged at $16,000 \mathrm{~g}$ for 10 min at $4^{\circ} \mathrm{C}$ to obtain the supernatant for assay. Ten milroliter supernatant was incubated with ninety microliter of mixture buffer overnight at room temperature, then read at $570 \mathrm{~nm}$. The results were expressed as a ratio to the concentration of the control cells.

\section{Lipid Peroxidation Assessment}

Lipid peroxidation was measured using a malondialdehyde (MDA) assay kit (Beyotime Biotech, Nanjing, China). In brief, cells were harvested by trypsinization and cellular extracts were prepared by sonicating in ice-cold RAPA (Beyotime Biotech, Nanjing, China). After sonication, lysed cells were centrifuged at $10,000 \mathrm{~g}$ for $20 \mathrm{~min}$ to remove debris. The supernatant was subjected to the measurement of MDA levels and the protein contents. We used a protein assay kit (Bio-Rad Laboratories, Hercules, USA) to quantify protein concentration. MDA levels were then normalized to milligram protein. MDA content was expressed as a ratio to the absorbance value of the control cells.

\section{Mitochondrial Membrane Potential Assay}

Mitochondrial membrane potential was assayed using JC-1 according to manufacture's instruction (Beyotime Biotech, Nanjing, China). Briefly, cells were cultured in 6-well plates with $3 \times 10^{5}$ cells per well. After $24 \mathrm{~h}$ of growth, cells were treated with SPIO-Serum at concentrations of $100 \mu \mathrm{g} \mathrm{Fe} / \mathrm{mL}$ for $24 \mathrm{~h}$. Staining with JC-1, the cells were analyzed by flow cytometry (BD Biosciences, Franklin Lakes, NJ, USA). The excitation wavelength of JC-1 is $488 \mathrm{~nm}$, and the approximate emission wavelength of the monometric and J-aggregate forms is 529 and $590 \mathrm{~nm}$.

\section{SPIO Nanoworms Uptake Assay}

The uptake was studied as described previously. ${ }^{26}$ Briefly, cells were incubated with SPIO or SPIO-Serum for $1 \mathrm{~h}$ or $4 \mathrm{~h}$, washed with PBS to remove the free nanoworms and passed over a Mini MACS magnetic column (Miltenyi Biotec) to separate IRON labeled from unlabeled cells. Magnetic cells from different groups were suspended in equal amounts of $1 \%(\mathrm{wt} / \mathrm{vol})$ BSA-PBS and concentrated on glass slides using cytospin (Thermo Fisher Scientific,
Rockford, IL, USA). The cells on slides were then fixed with $10 \%$ buffered formalin solution and stained with Hoechst nuclear stain (Thermo Fisher Scientific, Rockford, IL, USA). Random microscopic areas were used for cell counting.

\section{ROS Detection}

The average level of ROS was measured using a ROS assay kit DCFH-DA (Beyotime Biotech, Nanjing, China). Approximately $3 \times 10^{5}$ cells/well were seeded in 6-well plates overnight followed by the treatment of SPIOSerum for $24 \mathrm{~h}$. DCFH-DA was diluted to a final concentration of $10 \mu \mathrm{M}$. The cells were collected and suspended in diluted DCFH-DA in the dark at $37^{\circ} \mathrm{C}$ for $30 \mathrm{~min}$ and washed 3 times with PBS, and then samples were analyzed using an Accuri C6 Flow Cytometer (BD Biosciences, Franklin Lakes, NJ, USA).

\section{Mitochondrial ROS and Immunofluorescence Assay} SKOV3 cells $\left(5 \times 10^{4}\right)$ were seeded in 24 -well plates. After treatment, samples were harvested, washed with PBS, resuspended in $200 \mu \mathrm{L}$ of $5 \mu \mathrm{M}$ MitoSOX-Red, and left to incubate for $15 \mathrm{~min}$ at $37^{\circ} \mathrm{C}$. Cells were fixed in $4 \%(\mathrm{w} /$ v) paraformaldehyde/PBS for $20 \mathrm{~min}$ and then permeabilized with $0.1 \%$ Triton X-100 for 15 min. After blocking with bovine serum albumin for $30 \mathrm{~min}$, cells were incubated with primary antibody (Abcam, Cambridge, MA, USA) overnight at $4^{\circ} \mathrm{C}$. Cells were then incubated with FITC/Texas Green-conjugated secondary antibody (Proteintech, Chicago, IL, USA) at room temperature for $1 \mathrm{~h}$. The images were acquired using a ZEISS Imager Z2 Confocal microscope.

\section{Western Blot}

Cells were lysed in RIPA buffer with protease inhibitors. Lysates were cleared by centrifugation at $10,000 \mathrm{~g}$ for 15 min at $4^{\circ} \mathrm{C}$, boiled in loading buffer, and resolved using SDS-PAGE. Proteins were transferred to PVDF membranes and membranes were blocked with $5 \%$ milk, followed by incubation with primary antibodies overnight at $4^{\circ} \mathrm{C}$. Membranes were then incubated with HRP-conjugated secondary antibodies (Proteintech, Chicago, IL, USA). ECL reagent (Thermo Fisher Scientific, Rockford, IL, USA) was used for immunodetection and visualization using Syngene Bio Imaging (Synoptics, Cambridge, UK, USA).

\section{Plasmids and Transfection}

Trans-OE TM DNA TP53 was purchased from Genechem (Shanghai, China). Cells were transfected using 
transfection Reagent (Promega, Madison, MI, USA) according to the manufacturer's instructions.

\section{Statistical Analysis}

All experimental data represent at least 3 independent experiments and were presented as mean \pm standard deviation (SD) and carried out using Student's $t$-test. $P<0.05$ or $P<0.01$ were considered statistically significant difference. Statistical analysis was performed with GraphPad Prism 7.0 (La Jolla, CA, USA).

\section{Results}

\section{SPIO-Serum Labeled Ovarian Cancer Cells and Inhibited Their Viability}

The morphology and average size of SPIO nanoworms were determined by TEM (Figure 1A left). Incubating SPIO nanoworms in human serum at $37^{\circ} \mathrm{C}$ for $30 \mathrm{~min}$, TEM images showed that SPIO nanoworms maintain their overall shape after incubation with human serum. Moreover, serum-incubated particles showed patchy electron-dense protein clusters close to the iron oxide core (Figure 1A right).

Incorporation of SPIO and SPIO-Serum into ovarian cells following $1 \mathrm{~h}, 4 \mathrm{~h}$, or $24 \mathrm{~h}$ incubation was examined using a magnetic column sorting system. The number of magnetic cells treated by SPIO-serum is higher than that of SPIO either $1 \mathrm{~h}, 4 \mathrm{~h}$, and $24 \mathrm{~h}$ suggesting a timedependent response (Figure 1B). SKOV3 and A2780 cells treated with SPIO-Serum $(100 \mu \mathrm{g} \mathrm{Fe} / \mathrm{mL})$ exhibited positive blue staining while untreated cells had minimal blue staining consistent with the result of MACS isolation experiment (Figure 1C). Ovarian cancer cells, SKOV3 and A2780, were treated with SPIO or SPIO pre-incubated with human serum or fetal bovine serum (FBS). SPIO from 50 to $200 \mu \mathrm{g} \mathrm{Fe} / \mathrm{mL}$ and SPIO-FBS $(100 \mu \mathrm{g} \mathrm{Fe} /$ $\mathrm{mL}$ ) had minimal effect on the proliferation of human ovarian cancer cells (Figure 1D and F). In contrast, SPIOSerum from 50 to $200 \mu \mathrm{g} \mathrm{Fe} / \mathrm{mL}$, substantially reduced cell proliferation, suggesting that incubation of SPIO nanoworms in human serum inhibited ovarian cancer cells viability (Figure 1E).

\section{No Intact Nanoparticles Exist but Mitochondria Were Damage in SPIO-Serum Treated Cells}

In order to observe whether ovarian cells incorporated SPIO, transmission electron microscopy was used to observe the SKOV3 and A2780 cells. No obvious intact nanoparticles were found in cells (Figure 2). In the result of Figure 1C, the obvious increases in deep blue foci in the SPIO-Serum group was evidence of an increase in cellular iron ions. These results suggested that SPIO nanoparticles might be incorporated as iron ions in SKOV3 and A2780 cells after incubated with SPIO-Serum.

Mitochondria are major hubs of iron accumulation. ${ }^{27}$ Specially, iron overload usually caused mitochondria dysfunction as mitochondria is the target of ironmediated damage. ${ }^{28}$ As shown, TEM images presented that untreated ovarian cancer cells were intact and their mitochondria were linear or granular with an integral bilayer membrane structure. In contrast, SPIO-Seruminduced injury marked by decreased mitochondrial cristae, swollen mitochondria, and ruptured mitochondrial membranes, which generally associated with morphology of ferroptosis. Consistently, only SPIO-Serum reduced cell proliferation, while SPIO or SPIO-FBS had little effect on proliferation (Figure 1F). Together, these results demonstrated that iron oxide nanoparticles were most likely incorporated as iron ions, and even transported to mitochondria in SPIO-Serum treated cells. SPIO-Serum-induced ovarian cancer cells death was associated with increased intracellular iron ion levels.

\section{SPIO-Serum Induced Ferroptosis in Ovarian Cancer Cells}

We provided 6 observations supporting our belief that SPIO-Serum facilitated ferroptosis in ovarian cancer cells SKOV3 and A2780. 1) Supporting these observations we found that the ferroptosis inhibitors DFO or Fer-1 substantially increased the level of intracellular iron ovarian cancer cells survival when administered prior to treatment with erastin or SPIO-Serum (Figure 3A-E). 2) Mitochondrial damage is a distinct feature of ferroptosis. Using the JC-1 probe to detect mitochondrial membrane potential/damage in ovarian cancer cells, we found that red fluorescence was reduced in ovarian cancer cells treated with human SPIO-Serum, while green fluorescence was increased, consistent with mitochondrial damage (Figure 4A). 3) Intracellular ROS levels, determined by flow cytometry, increased after SKOV3 and A2780 cells were incubated with SPIO-Serum compared with untreated cells 


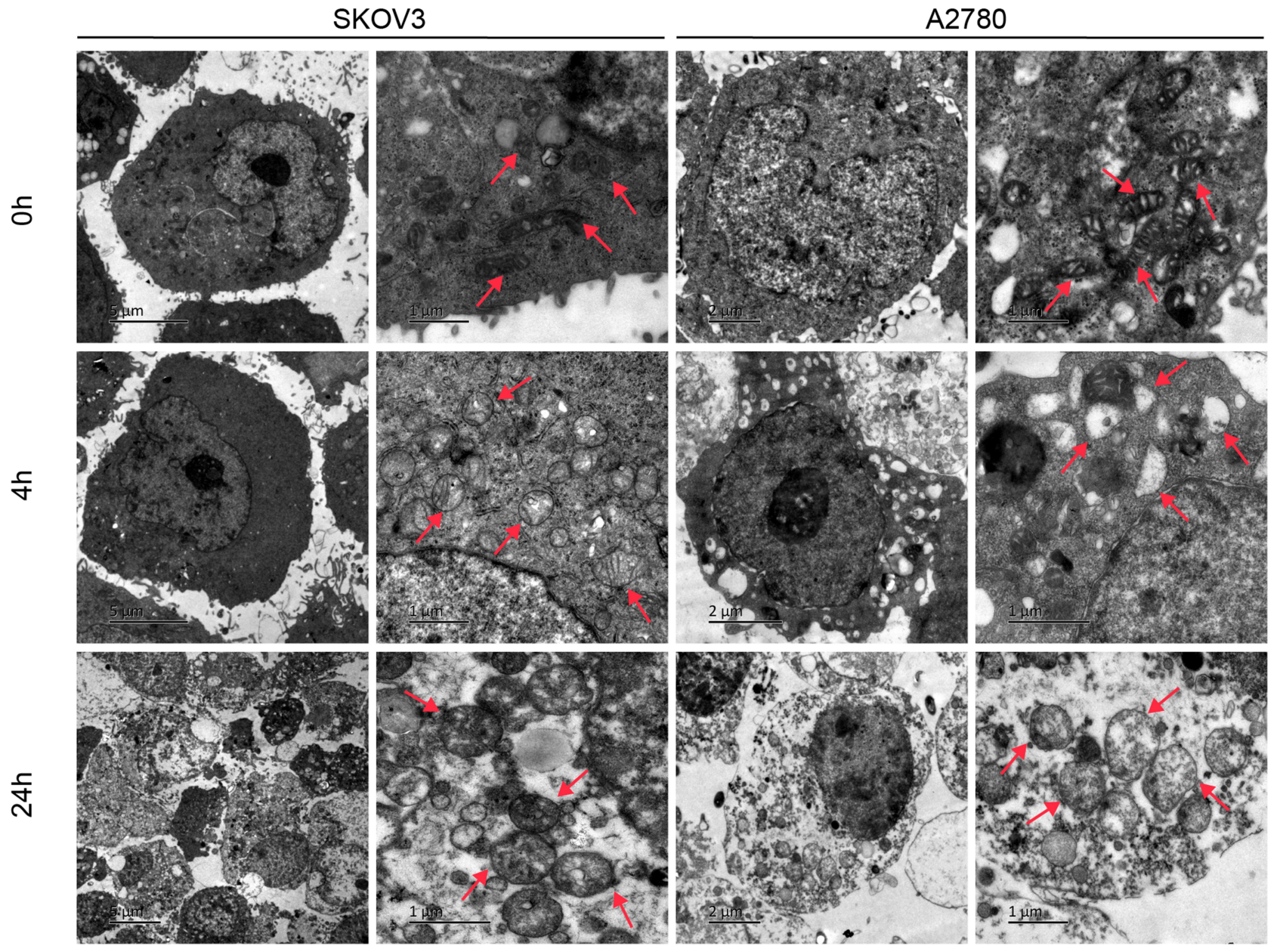

Figure 2 SPIO-Serum induced mitochondrial damage. TEM images of SKOV3 and A2780 ovarian cells treated with SPIO-Serum for $4 \mathrm{~h}$ or $24 \mathrm{~h}$ (arrow). SPIO-Serum-treated cells showed mitochondrial damage with mitochondrial outer membrane ruptured and mitochondria crista vanished.

(Figure 4B). MitoSOX Red, a mitochondrial superoxide indicator, detected elevated levels of mitochondrial ROS in SPIO-Serum treated cells. Pre-treatment cells with DFO and Fer-1 for $30 \mathrm{~min}$ still yielded lower ROS levels (Figure 4C). 4) Cells experiencing ferroptosis expressed higher levels of lipid peroxidation (MDA). ${ }^{29}$ SKOV3 and A2780 cells pre-treated with Fer-1 or DFO followed by SPIO-Serum treatment had lower levels of MDA than cells treated with SPIOSerum alone, results consistent with ferroptosis (Figure 4D). 5) Additionally, Western blot results showed that the expression level of GPX4 and $\mathrm{xCT}$ reduced in the ovarian cancer cells treatment with SPIO-Serum, it was consistent with occurrence of ferroptosis (Figure 4E and F). 6) $\mathrm{xCT}$ is a specific lightchain subunit of the cystine/glutamate antiporter system $\mathrm{x}_{\mathrm{c}}{ }^{-}$, promotes protection from oxidative stress and ferroptosis cell death. ${ }^{30}$ To analyze changes in the transport of extracellular cystine into the cells, the expression of $\mathrm{xCT}$ was examined. Western blot results showed that SPIO-Serum could inhibit the expression of $\mathrm{xCT}$ (Figure 4E and $\mathrm{F}$ ).

\section{SPIO-Serum Up-Regulated Transferrin (TF) and Transferrin Receptor (TFR) Expression}

TF and TFR have recently been identified to regulate ferroptosis by directly or indirectly targeting iron metabolism. ${ }^{31-33}$ To further define the role of SPIOSerum increasing intracellular iron, Western blot was used to detect the expression of TF and TFR, which were involved in iron metabolism and assayed iron accumulation. TF and TFR expression up-regulated (Figure 5A and B), and total iron increased in SKOV3 and A2780 cells after treatment with SPIO-Serum relative to untreated cells (Figure 5C). TF and TFR levels of SPIO-Serumtreated cells were statistically higher than control cells and SPIO treated cells, which consisted with intracellular iron. 
A

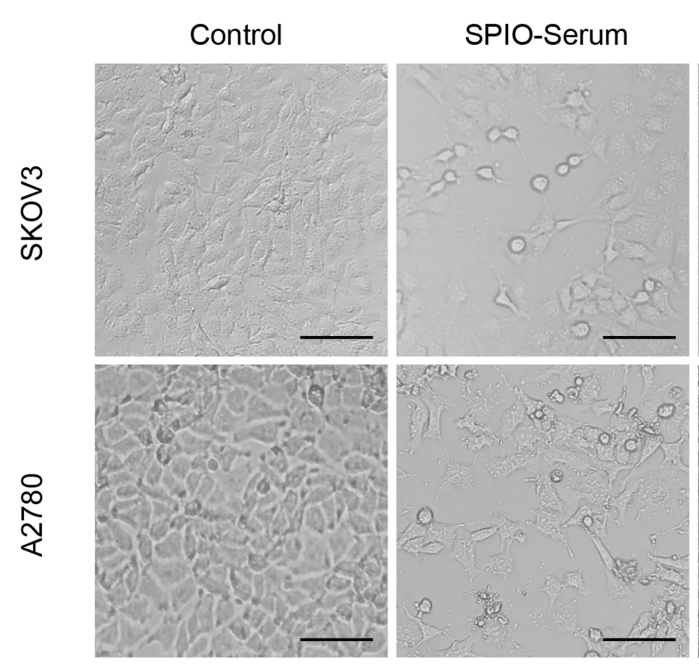

SPIO-Serum+DFO SPIO-Serum+Fer-1
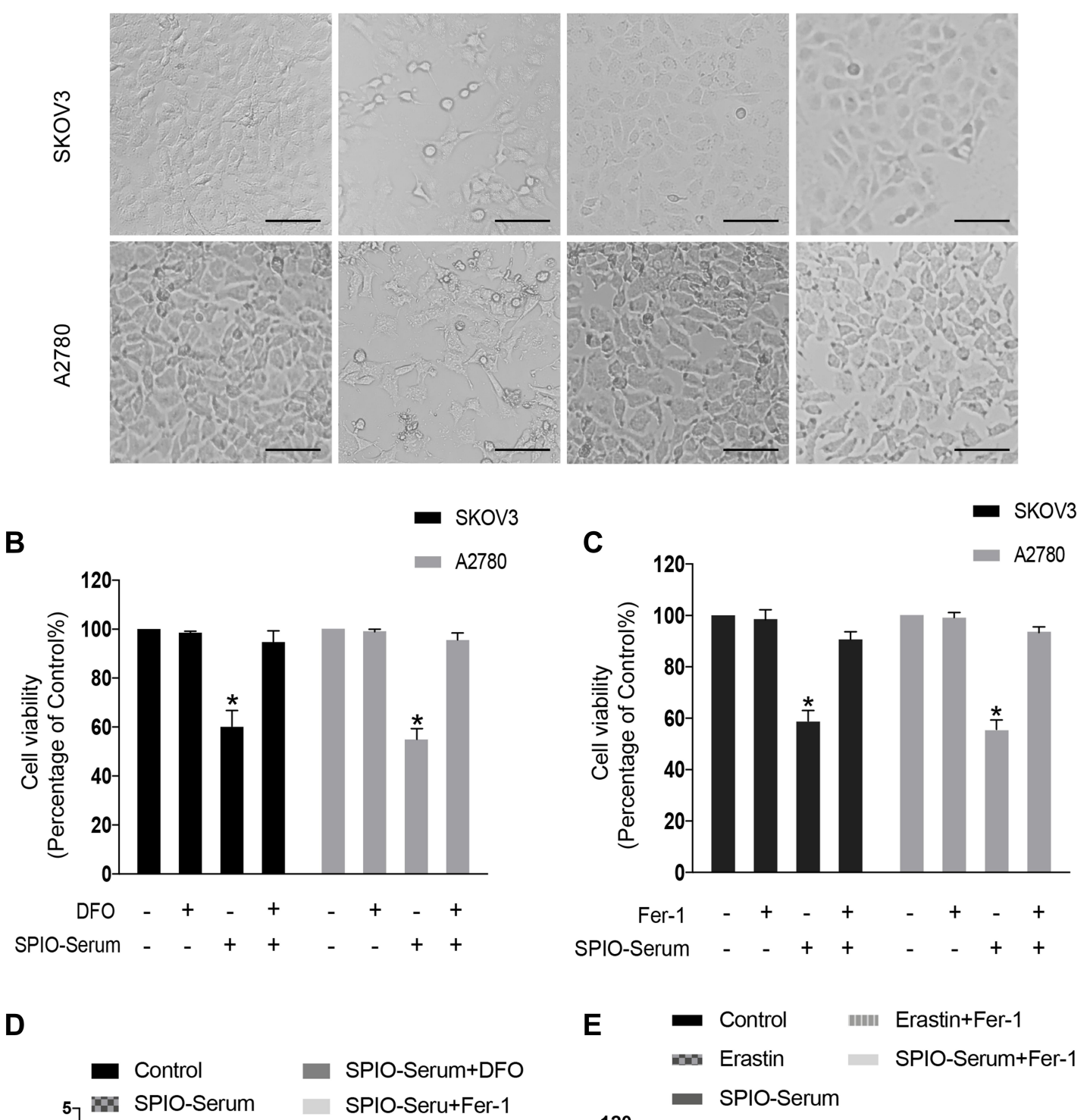
E Control 피 Erastin+Fer-1
Erastin SPIO-Serum+Fer-1
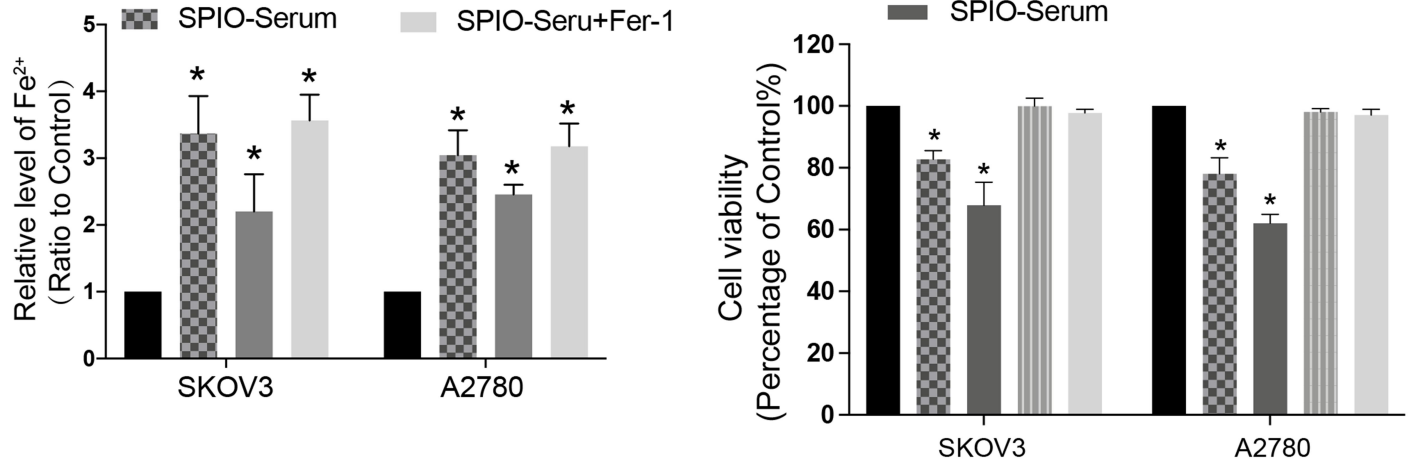

Figure 3 Ferroptosis of ovarian cancer cells induced by SPIO-Serum. (A) Optical microscopy images showed pre-treatment with DFO (40 mM) and Fer-I (50 nM) for 30 min, mitigated the effect of SPIO-Serum on ovarian cancer cell death (Scale bar: $40 \mu \mathrm{m}$ ). (B and C) Quantitative measurement of cell viability. The MTT assay results suggested that pre-treatment with $40 \mathrm{mM} \mathrm{DFO}$ (B) and $50 \mathrm{nM}$ Fer-I (C) for $30 \mathrm{~min}$, reduced the effect of SPIO-Serum on ovarian cancer cells death. (D) Total iron levels for $24 \mathrm{~h}$. The results showed that pre-treatment with DFO (40 mM) inhibited the ovarian cancer cells incorporated SPIO nanoparticles. (E) Ovarian cancer SKOV3 and A2780 cells were treated with erastin or SPIO-Serum for 24 h. MTT assay result showed that pre-treatment with Fer-I $(50 \mathrm{nM})$ for $30 \mathrm{~min}$, mitigated the effect of SPIO-Serum or erastin on ovarian cancer cells death. All data presented the mean \pm $\mathrm{SD}(\mathrm{n}=3) . * P<0.05$ vs control group.

Abbreviations: DFO, deferoxamine; Fer-I, ferrostatin-I. 
A

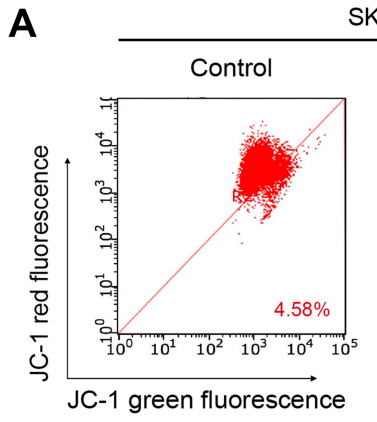

B

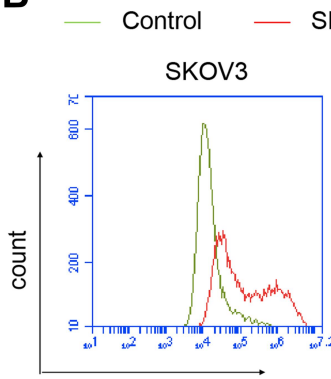

ROS green flurescence

C

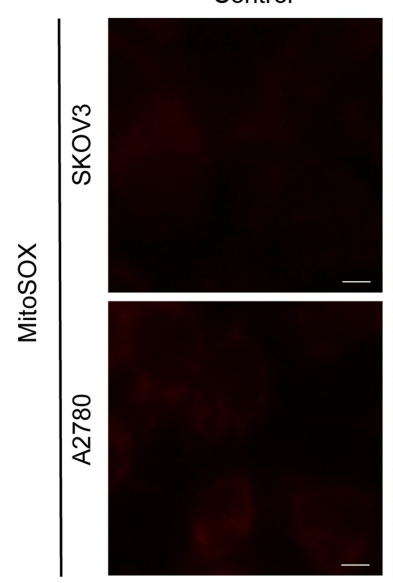

E

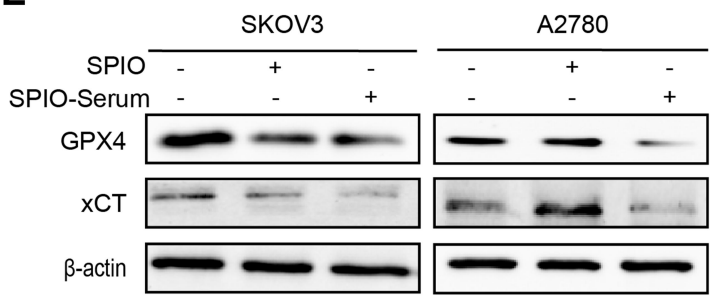

SKOV3

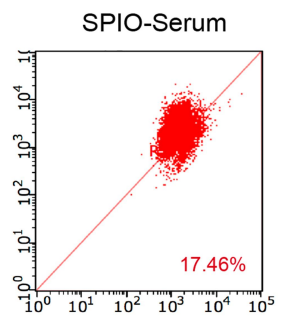

\section{D}

D
$\quad$ Control
SPIO-Serum

w SPIO-Serum+DFO

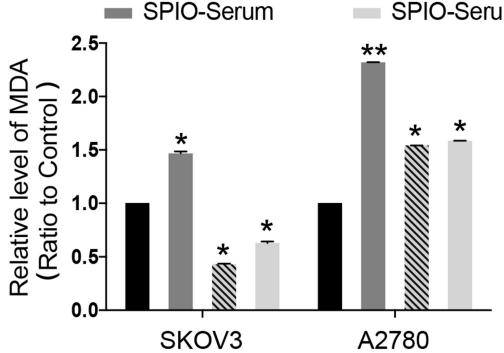

SPIO-Serum+DFO

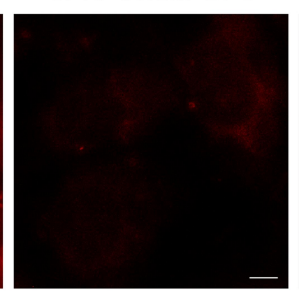

SPIO-Serum+Fer-1
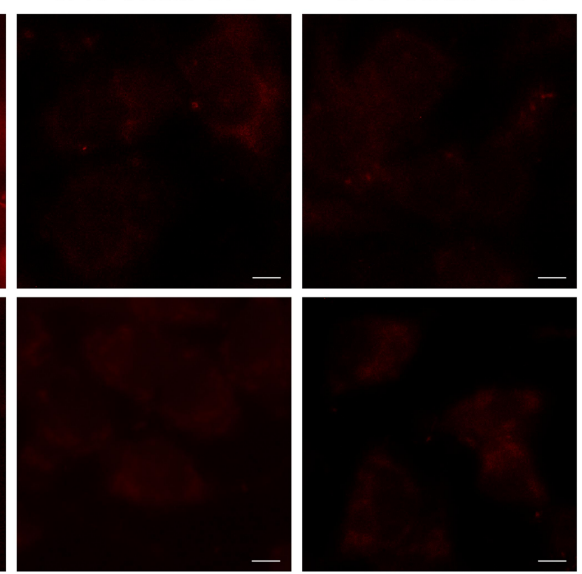

F Control $\square$ SPIO $\square$ SPIO-Serum

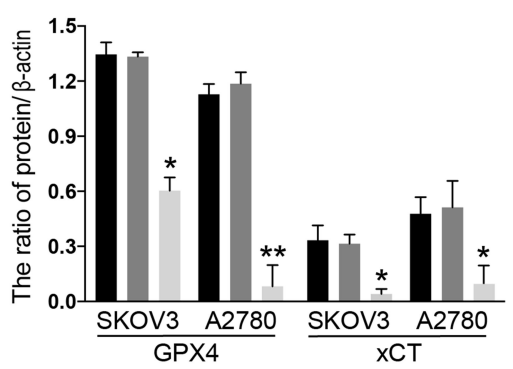

Figure 4 ROS levels in ovarian cancer cells induced by SPIO-Serum. (A) JC-I was used to detect mitochondrial membrane potential in SKOV3 and A2780 cells. The data showed that SPIO-Serum reduced mitochondrial membrane potential. (B) ROS probe DCFH-DA was used to detect the ROS levels inside ovarian tumor cells. The results revealed that the ROS levels increased in SKOV3 and A2780 after $24 \mathrm{~h}$ cultured with SPIO-Serum (100 $\mu \mathrm{g} \mathrm{Fe} / \mathrm{mL})$. (C) MitoSOX Red was used to detect the Mitochondria ROS of ovarian cancer after cultured with SPIO-Serum ( $100 \mu \mathrm{g} \mathrm{Fe} / \mathrm{mL}$ ). The fluorescence microscopic images showed that mitochondrial ROS production increased by $100 \mu \mathrm{g}$ Fe/mL SPIO-Serum, while pretreatment with DFO $(40 \mathrm{mM})$ or Fer-I $(50 \mathrm{nM})$ could mitigate this phenomenon (Scale bar: $10 \mu \mathrm{m})$. (D) MDA assay kit was used to detect the generation of MDA. Following pre-incubation of ferroptosis inhibitors, DFO $(40 \mathrm{mM})$ or Fer-I $(50 \mathrm{nM})$, cells were treated with SPIO-Serum (100 $\mu \mathrm{g} \mathrm{Fe} / \mathrm{mL})$. The results showed that both DFO and Fer-I reduced MDA generation which activated by SPIO-Serum. (E and F) Western blot analyzed GPX 4 and $x$ CTexpression in ovarian cancer cells SKOV3 and A2780 treated with SPIO-Serum. All data presented the mean \pm SD ( $=3$ ). $* P<0.05$ vs control group. $* * P<0.01$ vs control group.

Abbreviations: MDA, malonaldehyde; ROS, reactive oxygen species. 
A

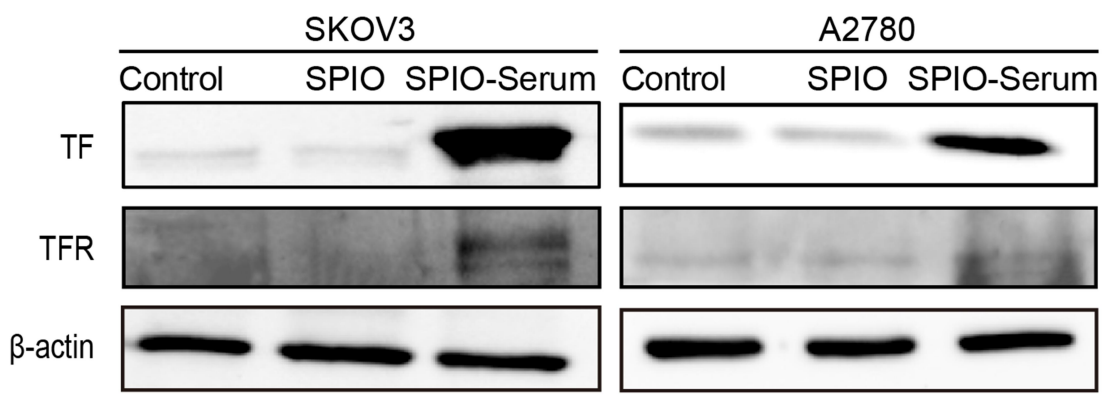

B

C
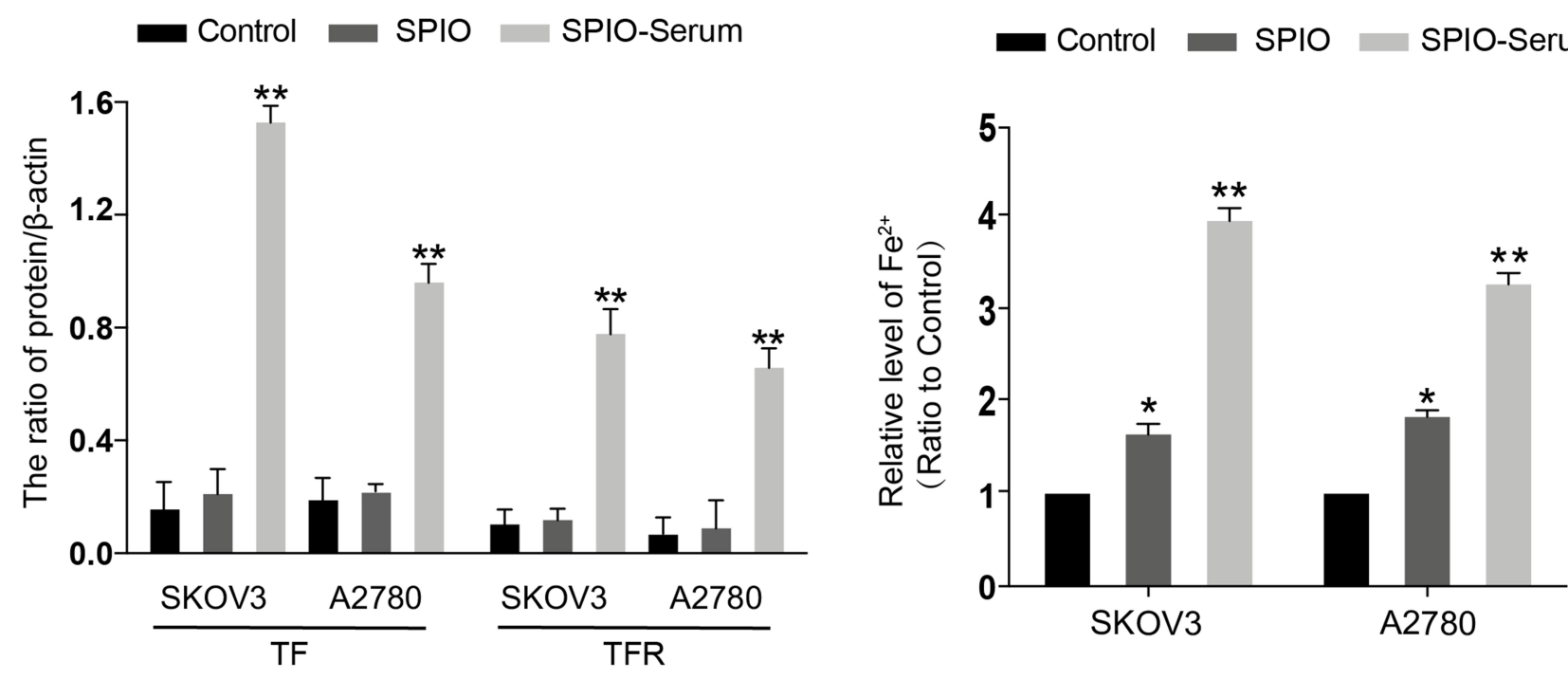

Figure 5 Effect of SPIO and SPIO-Serum on TF, TFR and relative iron levels in SKOV3 and A2780 cells. (A and B) Cells were treated with SPIO or SPIO-Serum at I00 $\mu \mathrm{g}$ Fe/ $\mathrm{mL}$ for $24 \mathrm{~h}$ and quantitatively analyzed for TF and TFR by Western blot. (C) Total iron levels. All data presented the mean $\pm S D(n=3)$. $* P<0.05$ vs control group. $* * P<0.01$ vs control group.

Abbreviations: TF, transferrin; TFR, transferrin receptor.

\section{p53 and SPIO-Serum Synergistically Promoted Ferroptosis in Ovarian Cancer Cells}

In order to explore synergistic interactions between p53 and SPIO-Serum, p53 was transfected in SKOV3 and A2780 cells. Western blot results showed that the expression of p53 was lower in SKOV3 and A2780 cells, but obviously higher in both transfected cells (Figure 6A and B). Light microscopy and MTT assay results indicated that the proliferation of ovarian cancer cells slightly reduced when overexpressed p53 or SPIO-Serum treated alone, suggesting that p53 synergistically worked with SPIOSerum to induce ovarian cancer cell death (Figure 6C and D). Further support for these observations came from Western blot showed that the expression of ferroptosisrelated proteins $\mathrm{xCT}$ and GPX4 in SKOV3 and A2780 cells were significantly down-regulated consistent with data in Figure 6A-D (Figure 6E and F). Subsequently, mitochondrial ROS and $\mathrm{xCT}$ expression were examined in ovarian cancer cells transfected p53 and treated with SPIO-Serum. As shown in Figure 6G, compared to singleagent groups, green fluorescence greatly reduced when transfected p53 prior to treatment with SPIO-Serum, indicating $\mathrm{xCT}$ expression further inhibited when p53 overexpression combined with SPIO-Serum. Consistently, red fluorescence from MitoSOX Red was significantly brighter in cells when transfected p53 prior to treatment with SPIO-Serum compared to single-agent and control groups. These data suggested $\mathrm{p} 53$ promoted human SPIO-Serum to accumulate excessive mitochondrial ROS (Figure 6G). Prussian blue staining results demonstrated that transfected p53 had no negative effect on the uptake of SPIO-Serum by ovarian cancer cells (Figure $6 \mathrm{H}$ ). 
A

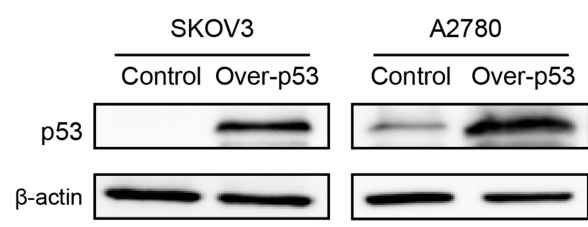

C

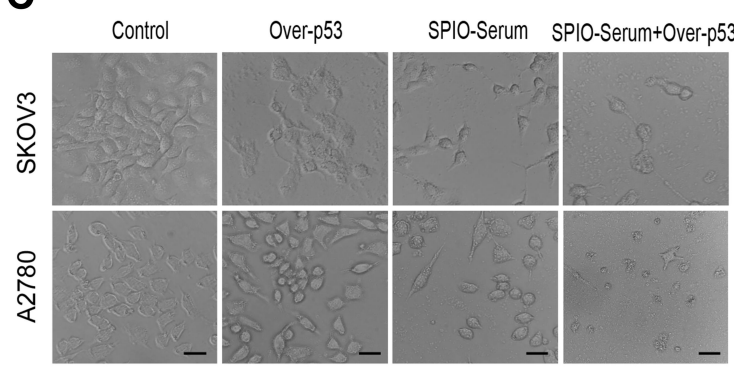

E

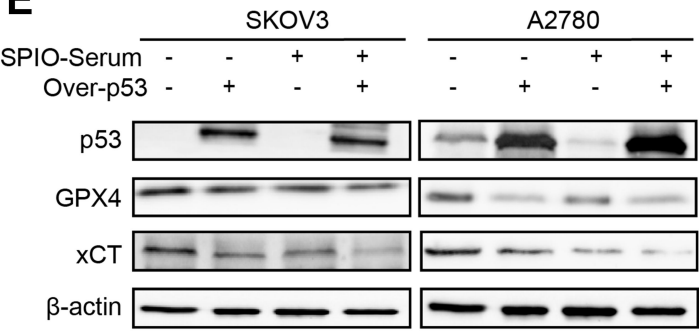

G
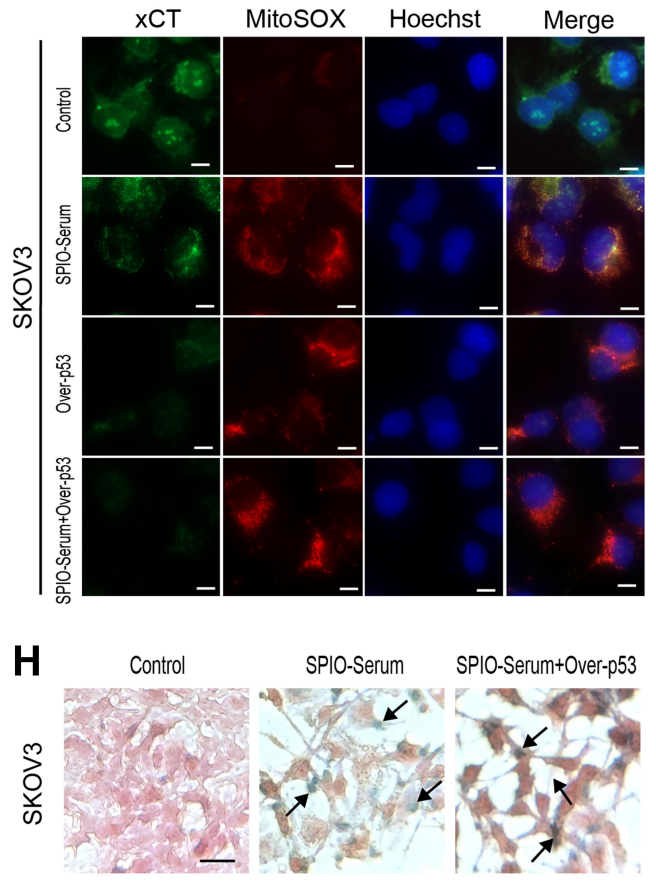

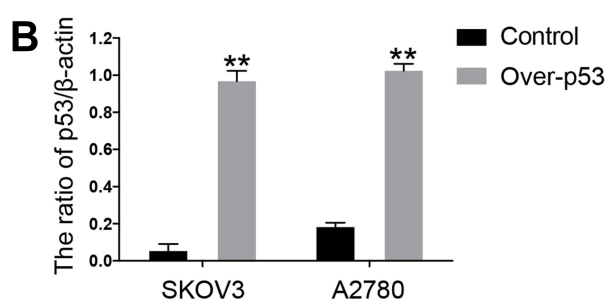

D

- Control En SPIO-Serum Over-p53 in sPIO-Serum+Over-p53

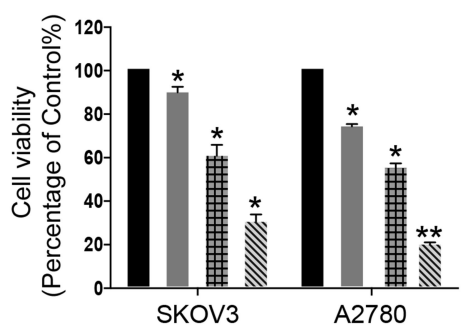

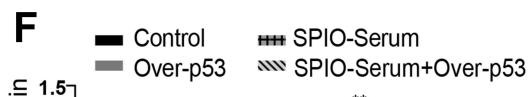

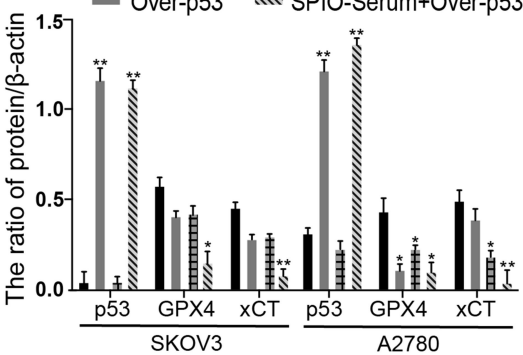

$x \mathrm{CT}$

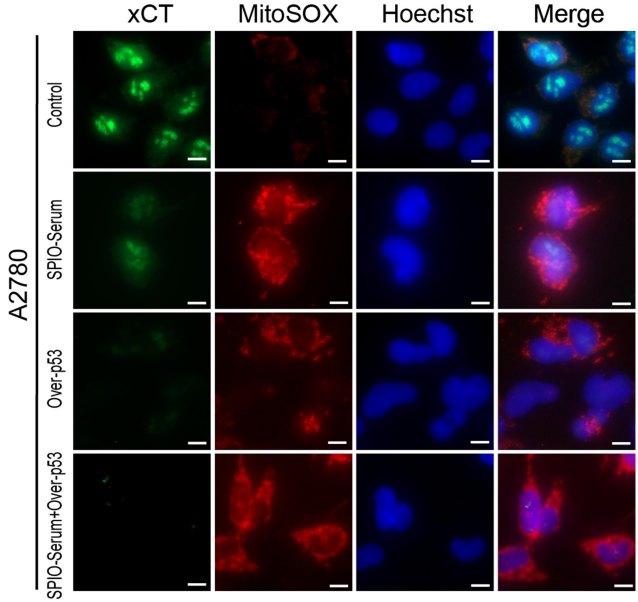

Control SPIO-Serum SPIO-Serum+Over-p53

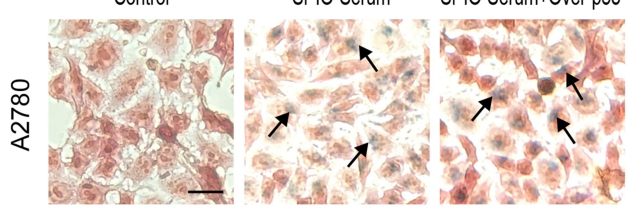

Figure 6 p53 promoted SPIO-Serum-induced ferroptosis. (A) Western blot detection of p53. (B) Quantification of p53 levels in SKOV3 and A2780 cells. (C) Light microscopy assessment of ovarian cancer cells survival (Scale bar: $20 \mu \mathrm{m}$ ). (D) SKOV3 and A2780 cells were treated with p53 overexpression, $100 \mu \mathrm{g}$ Fe/mL SPIO-Serum, p53 overexpression combined with $100 \mu \mathrm{g} \mathrm{Fe} / \mathrm{mL}$ SPIO-Serum for $24 \mathrm{~h}$, MTT assay was used to determine the cell viability. (E) SKOV3 and A2780 cells treated as indicated, Western blot was used to determine the ferroptosis-associated proteins $\times C T$ and GPX4. (F) p53, GPX4 and xCT levels. (G) xCT protein expression and mitochondrial ROS production were observed by fluorescence microscopy including control group, $100 \mu \mathrm{g} \mathrm{Fe} / \mathrm{mL}$ SPIO-Serum group, $\mathrm{p} 53$ overexpression group, and p53 overexpression combined with I00 $\mu \mathrm{g}$ Fe/mL SPIO-Serum group $($ Scale bar: $10 \mu \mathrm{m})$. (H) Prussian blue staining (Scale bar: $20 \mu \mathrm{m}$ ). All data presented the mean $\pm \mathrm{SD}(\mathrm{n}=3)$. $* P<0.05$ vs control group. $* * P<0.01$ vs control group. 


\section{Discussion}

Iron-oxide-based nanomaterials were designed for application in anticancer therapies as they catalyze the production of ROS via the Fenton reaction. Here we identified and established an essential inducing role for SPIO-Serum in ferroptosis. Ferroptosis is an iron and ROS-dependent cell death pathway, distinct from apoptosis, various forms of necrosis, and autophagy in terms of its morphology, biochemistry, and genetics. Simultaneous increases in iron accumulation and ROS production result in the induction of ferroptosis. In our study, treatment with SPIO-Serum triggered the cell death which could be linked to mitochondrial ROS production, mitochondrial damage and was dependent on the accumulation of both iron and lipid peroxidation products. We found that our SPIO nanoworms reduced the viability of SKOV3 and A2780 cells after a $30 \mathrm{~min}$ pre-incubation in human serum. Notably, SPIO nanoworms and SPIO nanoworms incubated with fetal bovine serum had no significant effect on cell viability, which suggested that human serum promoted the uptake of SPIO nanoworms under certain conditions. We confirmed our hypothesis using both MACS isolation and Prussian blue staining. We then went on to perform additional experiments designed to help uncover the specific mechanism underlying the ability of human serum to promote SPIO nanoworm uptake and induce cell death in ovarian cancer cells (summarized in Figure 7).

SPIO-Serum treatment was also shown to generate excessive lipid ROS in ovarian cells which could be reversed by DFO or Fer-1 pre-treatment. After internalization, SPIO nanoparticles were degraded into ferrous. Catalyzed by ferrous, $\mathrm{H} 2 \mathrm{O} 2$ is converted into highly reactive hydroxyl or superoxide radicals through Fenton reaction. ${ }^{41}$ Representative TEM images showed that SPIOserum treatment resulted in the disappearance of the mitochondrial cristae and the rupture of the outer mitochondrial membrane in a time-dependent manner. These morphological characteristics were consistent with ferroptosis but significantly different from regular apoptosis. This suggested that the uptake of SPIO nanoworms dysregulated the antioxidant defense system in the mitochondria resulting in the excessive accumulation of iron and ROSmediated mitochondrial damage. Abnormal increases in intracellular iron is believed to be the primary factor in ferroptosis. TF and TFR internalize the transferrin-iron complex, transporting extracellular $\mathrm{Fe}^{3+}$ into the cell. In this study, Western blot showed that both TF and TFR expression levels were up-regulated during ferroptosis and induced by SPIO-Serum. Iron assays verified that SPIOSerum treatment increased intracellular iron concentrations in ovarian cells. By contrast, neither the levels of TF and TFR nor the intracellular iron concentration was significantly changed when ovarian cancer cells were treated with SPIO or SPIO-FBS. This suggested that its incubation with human serum helped SPIO to increase the expression of TF and TFR thereby increasing its uptake in ovarian cancer cells.

Iron-induced lipid peroxidation is thought to be the key regulating factor in ferroptosis, and is also one of the criteria used to identify ferroptotic events. We found that SPIO-Serum down-regulated the expression of SLC7A11 and GPX4, resulting in the increased production of lipid peroxides in treated cells. SPIO-Serum treatment triggered ferroptosis disrupting the intracellular REDOX balance in these cells suggesting that the accumulation of ROS and the development of imbalances in iron homeostasis were interdependent events.

In addition, our results demonstrated that $\mathrm{p} 53$ expression promoted SPIO-Serum-induced ferroptosis. p53 plays an important tumor-suppressive function by mediating cell cycle arrest, apoptosis, and senescence. There is increasing evidence that p53 plays a pivotal role in ferroptosis, ${ }^{40}$ and our results suggested that a combination of p53 overexpression and SPIO-Serum treatment greatly inhibits the proliferation of ovarian cancer cells. In addition, our data suggested that p53 inhibited the expression of $\mathrm{xCT}$, a key mediator in the cysteine/glutamate reverse transportation system critical for sensitivity to ferroptosis. Moreover, p53 expression aggravated glutathione depletion by inhibiting $\mathrm{xCT}$ and promoted SPIO-Serum-induced accumulation of intracellular lipid peroxidation products thus aiding the development of SPIO-Serum-induced ferroptosis. On the other hand, Prussian blue staining showed that transfection with p53 or p53 in combination with SPIO-Serum did not negatively affect the uptake of iron nanoparticles by the ovarian cancer cells.

In summary, our study demonstrated that SPIO-Serum induced cell death was facilitated by ferroptosis. SPIOSerum induced ferroptosis by disrupting iron metabolism and mitochondrial and redox homeostasis, and appeared to be promoted by increased p53 expression. This research provides a theoretical basis for the development of iron 


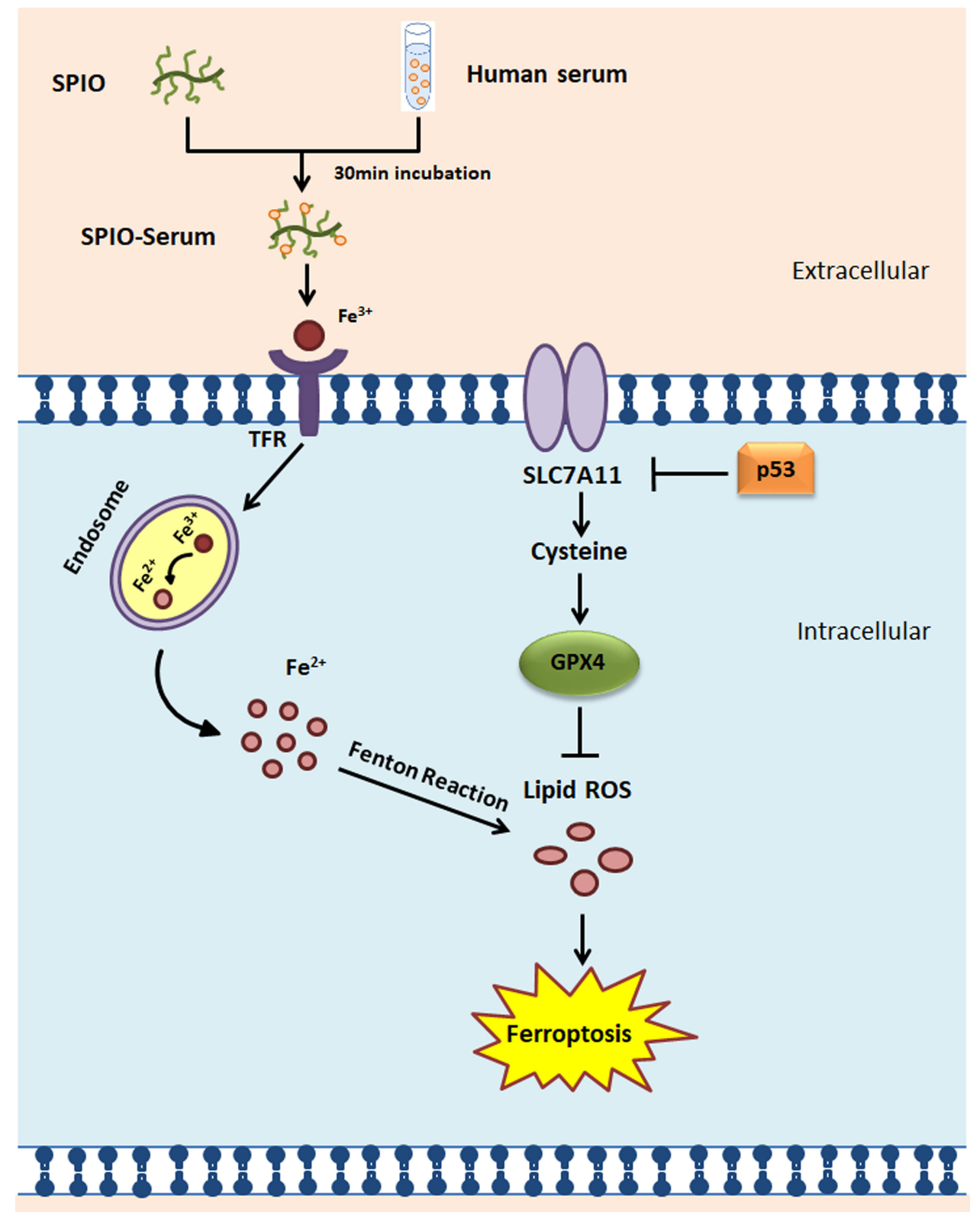

Figure 7 Schematic representation of SPIO-Serum-induced ferroptosis in ovarian cancer cells.

nanomaterials as novel tumor therapeutic drugs and may herald a new dawn for clinical anti-tumor treatments.

\section{Conclusion}

In conclusion, we presented an iron-based nanoparticles application inefficient tumor inhibition. Our results showed that the viability of ovarian cancer cells was effectively inhibited when treated with SPIO nanoworms preincubated with human serum. SPIO-Serum increased intracellular iron content, lipid peroxidation, and ultimately inducing ferroptosis in $\mathrm{p} 53$ promoting process in ovarian cancer cells.

\section{Acknowledgments}

We wish to thank Dr Dmitri Simberg, Department of Pharmaceutical Sciences, Skaggs School of Pharmacy and Pharmaceutical Sciences, University of Colorado Anschutz Medical Campus, for help providing superparamagnetic iron oxide nanoparticles. This study was funded by National Natural Science Foundation of China (81772794, 
81472419, 31771093), Jilin Provincial Industrial Innovation Project (2018C052-7), Jilin Provincial Research Foundation for the Development of Science and Technology Projects (20191004004TC), Jilin Province International Collaboration Project (201180414085GH), the Fundamental Research Funds for the Central Universities, JLU, the Program for JLU Science and Technology Innovative Research Team (2017TD-27, 2019TD-36).

\section{Disclosure}

The authors declare no conflicts of interest in this work.

\section{References}

1. Dixon SJ, Lemberg KM, Lamprecht MR, et al. Ferroptosis: an iron-dependent form of nonapoptotic cell death. Cell. 2012;149 (5):1060-1072.

2. Yang WS, Stockwell BR. Ferroptosis: death by lipid peroxidation. Trends Cell Biol. 2016;26(3):165-176.

3. Miller LD, Coffman LG, Chou JW, et al. An iron regulatory gene signature predicts outcome in breast cancer. Cancer Res. 2011;71 (21):6728-6737.

4. Cathcart JM, Banach A, Liu A, et al. Interleukin-6 increases matrix metalloproteinase-14 (MMP-14) levels via down-regulation of $\mathrm{p} 53$ to drive cancer progression. Oncotarget. 2016;7(38):61107-61120.

5. Maccio A, Madeddu C. Inflammation and ovarian cancer. Cytokine. 2012;58(2):133-147.

6. Dodson M, Castro-Portuguez R, Zhang DD. NRF2 plays a critical role in mitigating lipid peroxidation and ferroptosis. Redox Biol. 2019;23:101107.

7. Becker LB. New concepts in reactive oxygen species and cardiovascular reperfusion physiology. Cardiovasc Res. 2004;61(3):461-470.

8. Goossens V, Grooten J, De Vos K, Fiers W. Direct evidence for tumor necrosis factor-induced mitochondrial reactive oxygen intermediates and their involvement in cytotoxicity. Proc Natl Acad Sci U S A. 1995;92(18):8115-8119.

9. Li T, Liu X, Jiang L, et al. Loss of p53-mediated cell-cycle arrest, senescence and apoptosis promotes genomic instability and premature aging. Oncotarget. 2016;7(11):11838-11849.

10. Bykov VJN, Eriksson SE, Bianchi J, Wiman KG. Targeting mutant p53 for efficient cancer therapy. Nat Rev Cancer. 2018;18(2):89-102.

11. Kaiser AM, Attardi LD. Deconstructing networks of p53-mediated tumor suppression in vivo. Cell Death Differ. 2018;25(1):93-103.

12. Jiang L, Kon N, Li T, et al. Ferroptosis as a p53-mediated activity during tumour suppression. Nature. 2015;520(7545):57-62.

13. Liu DS, Duong CP, Haupt S, et al. Inhibiting the system $\mathrm{xC}(--$ /glutathione axis selectively targets cancers with mutant-p53 accumulation. Nat Commun. 2017;8:14844.

14. Dixon SJ, Stockwell BR. The role of iron and reactive oxygen species in cell death. Nat Chem Biol. 2014;10(1):9-17.

15. Valko M, Morris H, Cronin MT. Metals, toxicity and oxidative stress. Curr Med Chem. 2005;12(10):1161-1208.

16. Efferth T, Benakis A, Romero MR, et al. Enhancement of cytotoxicity of artemisinins toward cancer cells by ferrous iron. Free Radic Biol Med. 2004;37(7):998-1009.

17. Jain TK, Morales MA, Sahoo SK, et al. Iron oxide nanoparticles for sustained delivery of anticancer agents. Mol Pharm. 2005;2(3):194-205.

18. Douziech-Eyrolles L, Marchais H, Herve K, et al. Nanovectors for anticancer agents based on superparamagnetic iron oxide nanoparticles. Int $J$ Nanomedicine. 2007;2(4):541-550.
19. Wang S, Luo J, Zhang Z, et al. Iron and magnetic: new research direction of the ferroptosis-based cancer therapy. Am J Cancer Res. 2018;8(10):1933-1946.

20. Liu M, Liu B, Liu Q, et al. Nanomaterial-induced ferroptosis for cancer specific therapy. Coord Chem Rev. 2019;382:160-180.

21. Wang XG, Dong ZY, Cheng H, et al. A multifunctional metal-organic framework based tumor targeting drug delivery system for cancer therapy. Nanoscale. 2015;7(38):16061-16070.

22. Zheng DW, Lei Q, Zhu JY, et al. Switching apoptosis to ferroptosis: metal-organic network for high-efficiency anticancer therapy. Nano Lett. 2017;17(1):284-291.

23. Zhang C, Bu W, Ni D, et al. Synthesis of iron nanometallic glasses and their application in cancer therapy by a localized Fenton reaction. Angew Chem Int Ed Engl. 2016;55(6):2101-2106.

24. Huo M, Wang L, Wang Y, et al. Nanocatalytic tumor therapy by single-atom catalysts. ACS Nano. 2019;13(2):2643-2653.

25. Chen F, Wang G, Griffin JI, et al. Complement proteins bind to nanoparticle protein corona and undergo dynamic exchange in vivo. Nat Nanotechnol. 2017;12(4):387-393.

26. Inturi S, Wang G, Chen F, et al. Modulatory role of surface coating of superparamagnetic iron oxide nanoworms in complement opsonization and leukocyte uptake. ACS Nano. 2015;9(11):10758-10768.

27. Paul BT, Manz DH, Torti FM, Torti SV. Mitochondria and iron: current questions. Expert Rev Hematol. 2017;10(1):65-79.

28. Comporti M. Introduction-serial review: iron and cellular redox status. Free Radic Biol Med. 2002;32(7):565-567.

29. Yang WS, Kim KJ, Gaschler MM, et al. Peroxidation of polyunsaturated fatty acids by lipoxygenases drives ferroptosis. Proc Natl Acad Sci U S A. 2016;113(34):E4966-75.

30. Xie Y, Hou W, Song X, et al. Ferroptosis: process and function. Cell Death Differ. 2016;23(3):369-379.

31. Manz DH, Blanchette NL, Paul BT, et al. Iron and cancer: recent insights. Ann N Y Acad Sci. 2016;1368(1):149-161.

32. El Hout M, Dos Santos L, Hamai A, Mehrpour M. A promising new approach to cancer therapy: targeting iron metabolism in cancer stem cells. Semin Cancer Biol. 2018;53:125-138.

33. Imai $\mathrm{H}$, Matsuoka $M$, Kumagai $T$, et al. Lipid peroxidation-dependent cell death regulated by GPx4 and ferroptosis. Curr Top Microbiol Immunol. 2017;403:143-170.

34. Shen Z, Liu T, Li Y, et al. Fenton-reaction-acceleratable magnetic nanoparticles for ferroptosis therapy of orthotopic brain tumors. $A C S$ Nano. 2018;12(11):11355-11365.

35. Yu H, Guo P, Xie X, et al. Ferroptosis, a new form of cell death, and its relationships with tumourous diseases. J Cell Mol Med. 2017;21 (4):648-657.

36. Stockwell BR, Jiang X. The chemistry and biology of ferroptosis. Cell Chem Biol. 2020;27(4):365-375.

37. Wang Z, Ding Y, Wang X, et al. Pseudolaric acid B triggers ferroptosis in glioma cells via activation of Nox4 and inhibition of $\mathrm{xCT}$. Cancer Lett. 2018;428:21-33.

38. Li H, Qian ZM. Transferrin/transferrin receptor-mediated drug delivery. Med Res Rev. 2002;22(3):225-250.

39. Lane DJ, Chikhani S, Richardson V, Richardson DR. Transferrin iron uptake is stimulated by ascorbate via an intracellular reductive mechanism. Biochim Biophys Acta. 2013;1833(6):1527-1541.

40. Gnanapradeepan K, Basu S, Barnoud T, et al. The p53 tumor suppressor in the control of metabolism and ferroptosis. Front Endocrinol (Lausanne). 2018;9:124.

41. Gokduman K. Sensitization of cisplatin-resistant ovarian cancer cells by magnetite iron oxide nanoparticles: an in vitro study. Nanomedicine (Lond). 2019;14(24):3177-3191. 
International Journal of Nanomedicine

\section{Publish your work in this journal}

The International Journal of Nanomedicine is an international, peerreviewed journal focusing on the application of nanotechnology in diagnostics, therapeutics, and drug delivery systems throughout the biomedical field. This journal is indexed on PubMed Central, MedLine, CAS, SciSearch ${ }^{\mathbb{R}}$, Current Contents ${ }^{\mathbb{B}} /$ Clinical Medicine,
Journal Citation Reports/Science Edition, EMBase, Scopus and the Elsevier Bibliographic databases. The manuscript management system is completely online and includes a very quick and fair peer-review system, which is all easy to use. Visit http://www.dovepress.com/ testimonials.php to read real quotes from published authors. 